\title{
Surgical treatment of muscle injury. A review of current literature and indications
}

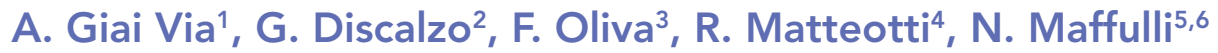 \\ 1 Orthopaedics and Traumatology, department of surgery, Ospedale Sant'Anna, San Fermo della Battaglia, \\ Como, Italy \\ 2 University of Varese, School of Medicine. Orthopaedics and Traumatology, department of surgery, Ospedale \\ Sant'Anna, San Fermo della Battaglia, Como, Italy \\ 3 Department of Musculoskeletal Disorders, School of Medicine and Surgery, University of Salerno, Salerno, Italy \\ ${ }_{4}$ Orthopaedics and Traumatology, department of surgery, Umberto Parini Hospital, Aosta, Itlay \\ ${ }^{5}$ Department of Musculoskeletal Disorders, School of Medicine and Surgery, University of Salerno, Salerno, Italy \\ 6 Queen Mary University of London, Barts and the London School of Medicine and Dentistry, Centre for Sports \\ and Exercise Medicine, Mile End Hospital, London, England
}

\section{CORRESPONDING AUTHOR:}

Alessio Giai Via

Orthopaedics and Traumatology

Department of Surgery

Ospedale Sant'Anna

San Fermo della Battaglia

Como, Italy

E-mail: alessiogiaivia@hotmail.it

DOI:

10.32098/mltj.02.2020.15

LEVEL OF EVIDENCE: $3 a$

\begin{abstract}
SUMMARY
Introduction. Muscles lesions are common sport-related injuries. They are usually treated conservatively with good outcomes. However, large structural muscle injuries (type 4 according to I.S.Mu.L.T. classification) are a challenge for physicians. Often, patients may suffer from discomfort and residual pain, functional impairment, and the rate of complications and re-injury rate is high. Furthermore, the lack of clear indications does not help physicians in the decision process.

Methods. We performed a systematic review of four databases (PubMed, Google scholar, EMBASE, Cochrane Library) using the Preferred Reporting Items for Systematic reviews and Metanalysis (PRISMA) guidelines. Level I (RCT), II, III and level IV studies (case series) were included. We also searched for biomechanical and animal studies.

Results. Surgical repair of type IV muscle injuries seems to provide better outcomes and higher rate to return to sport than conservative treatment, although surgical repair is not supported by level I or II studies. The suture of the muscle fibers together with the epimysium increases the mechanical resistance of the suture and reduces the risk of pull-out. This technique allows earlier mobilization, promotes healing and reduces scar formation. Conclusions. In this article, we try to explain the rational to suture a closed muscle tear, summarize the proper surgical indications, and show the proper suture technique.
\end{abstract}

\section{KEY WORDS}

Muscle injury, rebabilitation, return to play, surgical treatment, skeletal muscle suture.

\section{INTRODUCTION}

Muscle injuries are common, and they are usually managed conservatively with good results. However, complete or sub-total structural muscle injuries (type 4 according to I.S.Mu.L.T. classification - table I) are a challenge for clinicians and athletes because of the high complications and re-injury rate, residual pain, and possible functional impairment (1). Furthermore, the lack of clear indications does not help physicians in the decision process. The main concern is the poor capacity of muscle tissue to regenerate itself. More- over, there are technical difficulties in performing an effective suture. Finally, there is not yet an evidence-based rehabilitation protocol for these lesions (2). In such difficult cases, primary surgical suture has been suggested by some authors. We reviewed the current literature, and we to tried to answer five questions: 1) why a massive muscle injury should be treated surgically, 2) which are the indications, 3) which is the most effective surgical technique, 4 ) which are the outcomes after the surgical repair of a massive muscle injury, and 5) what are the most common postoperative complications. 
Table I. This is a schematic representation of the I.S.Mu.L.T. classification of muscle injuries (1).

\begin{tabular}{|c|c|c|}
\hline \multicolumn{3}{|c|}{ Direct injury } \\
\hline & & Contusion \\
\hline & & Laceration \\
\hline \multirow[t]{6}{*}{$\begin{array}{l}\text { Indirect } \\
\text { injury }\end{array}$} & $\begin{array}{l}\text { Non-structural } \\
\text { injuries }\end{array}$ & 1A: fatigue injury \\
\hline & & $\begin{array}{l}\text { 1B: DOMS (Delayed Onset of } \\
\text { Muscle soreness) }\end{array}$ \\
\hline & & $\begin{array}{l}\text { 2: injury related to neuromuscular } \\
\text { disorder }\end{array}$ \\
\hline & $\begin{array}{l}\text { Structural } \\
\text { injuries }\end{array}$ & $\begin{array}{l}\text { 3A: minor partial injury, involving } \\
\text { one or more primary fascicles } \\
\text { within a secondary bundle }\end{array}$ \\
\hline & & $\begin{array}{l}\text { 3B: partial injury involving at least } \\
\text { one secondary bundle, but less } \\
\text { than } 50 \% \text { of the cross section of } \\
\text { the muscle belly }\end{array}$ \\
\hline & & $\begin{array}{l}\text { 4: subtotal or total tear, involving } \\
\text { more than the } 50 \% \text { of the cross } \\
\text { section or the entire muscle fibres, } \\
\text { at the MTJ or muscle belly. }\end{array}$ \\
\hline
\end{tabular}

\section{MATERIAL AND METHODS}

We systematically searched in four databases (PubMed, Google scholar, EMBASE, Cochrane Library) using the Preferred Reporting Items for Systematic reviews and Metanalysis (PRISMA) guidelines. We used the key words "muscle belly, muscle injury, muscle laceration, repair and muscle suture". The article research was extended from 1978 to December 2019/January 2020. Level I (RCT), II, III and level IV studies (case series) have been included. We also search for biomechanical and animal studies. Scientific papers excluded are narrative review, systematic review, case report or technical notes. The study has been performed according the international and ethical standards of the journal (3).

\section{RESULTS}

The search provided a total of 75 articles. Thirty-one studies were included in this review. The others have been excluded because they did not meet the inclusion criteria. In particular, several papers were excluded because they focused only on tendon injury or described a surgical technique with no outcome data.

\section{Why should we suture a muscle injury?}

Massive type 4 muscle tears are rare in ordinary orthopaedic practice, but they can produce marked negative consequences and disability for patients, even in the long-term. Although a torn muscle can heal, this process leads to replacement with sclero-fibrous tissue which has poor elastic, mechanical properties, and contractile capability. Moreover, massive muscle tears heal slowly and often incompletely, leaving a mass of scarred and immature tissue. This results in a reduction of contractile force and elastic properties of the muscular belly, alteration of strength transmission and may predispose the patient to further injury. Animals studies showed that immobilization to allow healing can lead to the development of scar tissue $(4,5)$. On the contrary, early mobilization promotes healing and proper orientation of muscle fibers in a more orderly manner, as well as reducing the formation of scar tissue and the loss of elasticity (5). Early mobilization, moreover, reduces muscle atrophy, improving overall functional recovery after injury. Naturally, early mobilization after surgery require the muscle repair to be reliable.

\section{Which are the indications for muscle surgical repair?}

In the case of a large muscle laceration, urgent surgical repair is intuitive and mandatory (figure 1). In the case of a closed, indirect muscle injury, the choice is much more difficult. Currently, there is no scientific evidence about surgical treatment of muscle tears, and the indication is discussed case by case, according to the kind of patient and functional demands.

According to the available literature, all patients who underwent surgical repair of an acute muscle injury (within 4 weeks), sustained a complete or sub-total injury of the muscular belly or at the myotendinous junction (type 4 according I.S.Mu.L.T.) $(6,7,8)$. The indications for surgical repair of a chronic injury were pain and/or limitation during sporting or daily life activities subjective or objective loss of strength compared to contralateral side, fatigue, chronic pain even at rest $(9,10,11)$, There are no articles published about hematomas evacuation and muscle suture after a direct trauma (table II).

The operative timing is extremely variable. In all the examined studies, acute injuries are those which were treated within 4 weeks of the initial trauma, while chronic injuries have been treated from 4 weeks to more than 1 year later. Better functional results and recovery were reported in patients operated within 4 weeks. However, there is still no clear evidence on the ideal timing for surgery $(8,10)$. 
Table II. Indications for surgical repair of muscle injuries.

\begin{tabular}{ll}
\hline Acute Muscle tear $(<4$ weeks) & Chronic muscle tear $(>\mathbf{4}$ weeks $)$ \\
\hline Type 4 muscle injury & Young age \\
\hline Young age & Pain during sport activity \\
\hline High level sport, intensity and frequency & Limitations in sport activity \\
\hline Persistence of pain after 1-2 weeks following intense physiotherapy & Fatigue \\
\hline Open Wound & Loss of strength compared with contralateral side \\
\hline & Pain and limitations during activities daily life \\
\hline
\end{tabular}

Moreover, there is no agreement in literature about the age of patients. Usually patients are young, between 18 and 43 years, but there is not a real limit of age beyond which the intervention is not indicated. Finally, we don't know if the gender of the patients could affect the final outcome.

\section{Which is the most effective surgical technique?}

The suture of a muscular belly is technically demanding because muscular tissue has unique characteristics. First, the suture is more difficult because of the low resistance of the muscle tissue, which determines a high rate of fail-

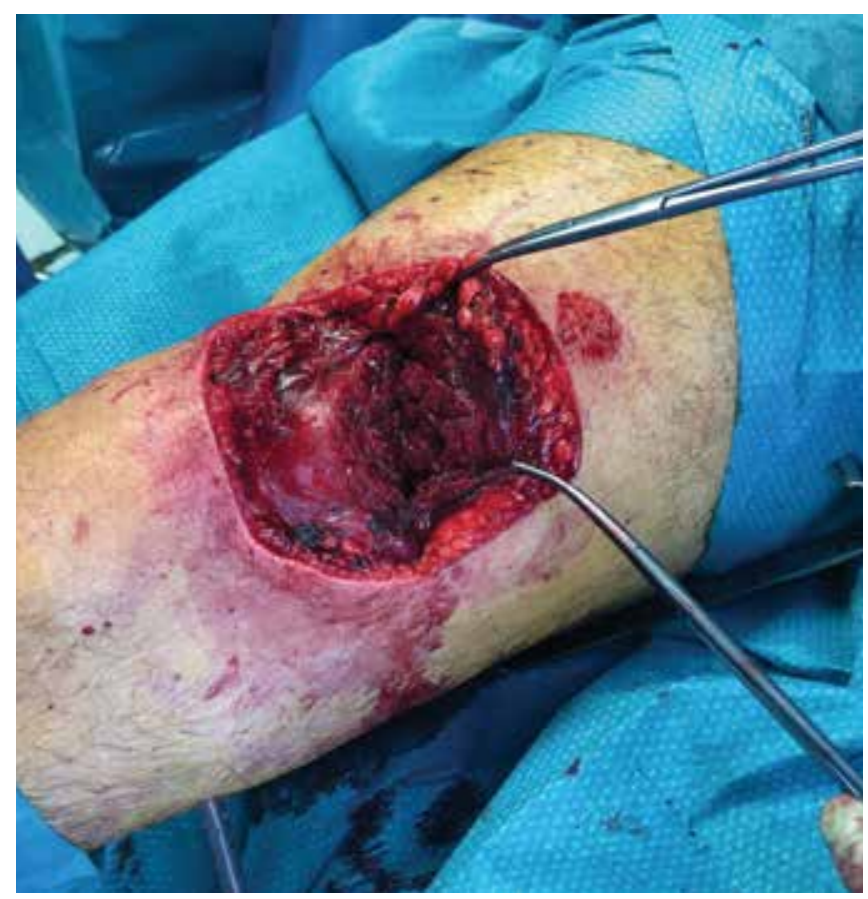

Figure 1. Complete cutting wound of the rectus femoris, vastus intermedius, and partial tear of the vastus lateralis following a ski downfall. ures and stitches pull-outs. Indeed, biomechanical studies on animals show that muscle fibers are the weakest part of the suture (12). The muscle fibers are parallel to the vector through which force is applied, and this makes the suture more subject to failure (13).

As previously mentioned, early mobilization promotes wound healing, but early mobilization needs a strong suture to withstand the forces applied. A secure muscle repair is not easily achievable, and studies on surgical techniques are extremely limited. Muscle suturing techniques can be schematically divided into simple and complex. To the first group belong the figure-of-eight suture and the horizontal mattress sutures, while to the second ones the modified Kessler and Masson-Allen techniques. When the repair also includes the suture of the epimysium or perimysium, the technique is called combined. Currently there is no evidence of which is the best technique.

Seven biomechanical studies were selected in order to understand which is the most effective surgical technique for muscle injury. Skeletal muscle is organized by its connective tissue components with epimysium surrounding the muscle as a connective tissue sheath, perimysium surrounding bundles of myofascicles, and endomysium surrounding myocytes. These studies showed that including the epimysium improved the tensile strength and reduced the pull-out of the sutures. In 2005, Krag et al. (14) demonstrated that the incorporation of the epimysium into muscle repair significantly improved the biomechanical properties of sutured muscle bellies when compared with repairs with perimysium. The epimysium is a thick fibrous sheath made of two layers, and the incorporation of the epimysium was biomechanically superior to muscle repair without epimysium (mean maximum load of $30.4 \mathrm{~N}$ compared to $19.2 \mathrm{~N}$ ) (14). In the same year, the same group published an animal study comparing the tensile strength between the Kessler and combined techniques (modified Mason-Allen for the fibers plus the peripheral suture for the epimysium) (13). 
The latter technique showed a tensile strength two time higher the Kessler. More recently, He at al. (15) compared three different types of sutures: simple mattress suture, Kessler-type suture, and Mason-Allen combined suture. The Kessler and Mason-Allen techniques showed similar tensile strength (15.5 N and $13.2 \mathrm{~N})$, and both were superior to simple stitches $(4.4 \mathrm{~N})$. Crow et al.16 proposed the use of a collagen scaffold (SIS - Small Intestinal Submucosa). According to the authors, this biological scaffold would favor wound remodeling, thus improving the healing and increasing the mechanical resistance of the suture. Recently, Goyal et al.17 compared a self-locking thread suture (V-LOC®, barbed suture) with a normal non-resorbable suture (Ethibond $\left.{ }^{\circledR}\right)$, and they found that barbed suture increased the load to failure and decreased the displacement of the repair site compared to normal suture. Repair of neglected injury is more difficult due to the scar tissue, muscle stumps retraction and the loss of elasticity. Therefore, some authors proposed an augmentation technique with LARS ligament ${ }^{\circledR}$ (Ligament Augmentation and Reconstruction System) in one case of a neglected tear of the rectus femoris muscle in a 17 -yearsold male football player (18). They reported that the use of LARS ligament ${ }^{\circledR}$, as reinforcement of the muscular suture, allowed immediate full passive mobilization of the knee, early graduated physiotherapy programme, and that the patient was able to return to running and his previous level of sport without any restrictions. However, no other studies on the augmentation device have been published in literature.

\section{What are the outcomes after the surgical repair of a massive muscle injury?}

The evidence of surgical treatment of type 4 muscle injuries is low, because few case series and case reports are reported in literature. Furthermore, there are no level I studies comparing surgical treatment with conservative management. Therefore, results were analysed according the available studies and the involved muscle (table III).

\section{Biceps brachii muscle}

In 2002 Krag et al. (6) published a retrospective case control study on patients who suffered closed transection of the biceps brachii belly. Nine patients treated surgically have been compared with 3 patients treated conservatively. All patients were paratroopers who suffered the same injury during a parachute jump. The average age was 21 years old, range 18-26. All patient fully recovered the function of their arm at final follow-up, but the authors found significant improvements in terms of function and satisfaction in patients who received surgical repair compared to those treated non-surgically. The cosmetics was also better in patient treated surgically. No complications were reported in either group. In conclusion, the authors recommended the surgical repair for patients who present a tear greater than $95 \%$ of muscle diameters. Two other studies have been also published, for a total of 23 patients. $(6,18)$. The authors agreed that surgical treatment is recommended when the tear is greater than $50 \%$ of the biceps brachii belly (type 4 according to I.S.Mu.L.T. classification)

Table III. Clinical studies regarding the suture of muscle injury.

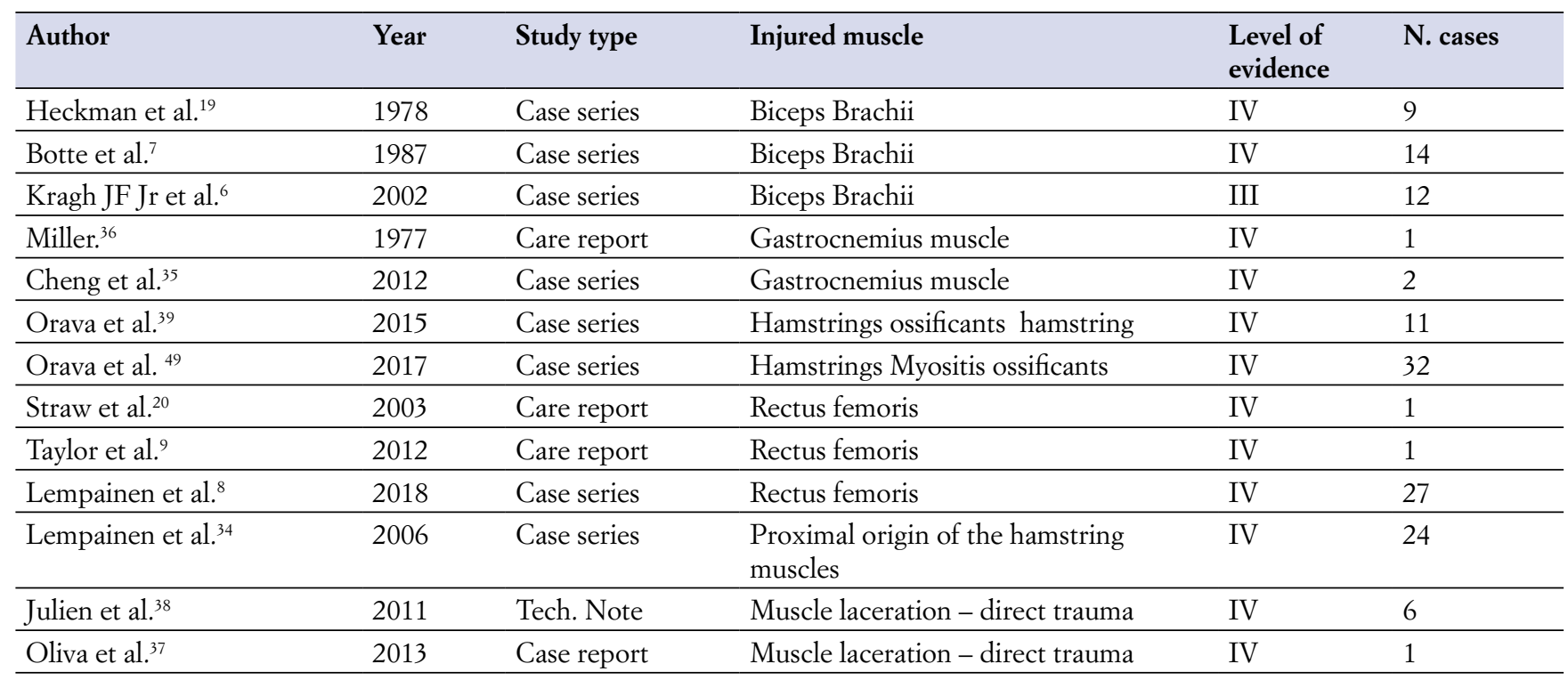




\section{Rectus Femoris muscle}

In 2018 Lempainen et al. (8) published a study on 27 elite football players treated surgically for rectus femoris grade III muscle injury (type 4 according I.S.Mu.L.T). Patients who suffered for injury of the direct or reflex head were excluded. The indications for surgical treatment complete tear of the muscle belly, that was confirmed at the MRI, pain, objective and subjective strength loss, functional limitations, re-injury, and chronic pain on injured area. The timing of surgery was different, 8 patients were treated within 4 weeks from injury (acute injuris), while 19 cases from 1 months to 1 year (neglected injuries). Good to excellent results have been reported in $74 \%$ of athletes, and most of patients $(20$ patients) returned to practice sports at the same preoperatory level, without pain limitation, or with a little pain that did not interfere with sporting activities. Patients returned to compete 5 months after surgery on average. Only in one case of chronic injury, the patient referred pain and limitations also in activities daily life, and a second surgery was performed.

Two case reports on young players (aged 17 and 22 years old) suffering from chronic muscle injury of rectus femoris have been reported $(18,19)$. Both patients referred pain and functional impairment, even after a complete and specific rehabilitation program. At the clinical examination, the patients had hypotrophy of the quadriceps, a loss of strength about $60 \%$ compared with contralateral side, fatigue, and they were not able to return to sport. In the first case the injury occurred at the muscle belly, just below the muscle-tendon junction, while in the second case the rupture involved the proximal muscle-tendon junction. Both players return to play football at the same preoperatory level, and they were satisfied with the surgery.

\section{Hamstring muscle}

Although hamstring muscle injuries are common, especially in athletes, there are currently no clear indications about their surgical treatment (figure 2). The lack of scientific evidence may be also the result of a confusing terminology in the literature.

Firstly, the injured area should be defined as proximal, middle third, distal (1). Only injuries of the proximal third and insertion have been widely described in literature, therefore, when we usually read about hamstrings ruptures, authors often refer to proximal injuries only $(20,21)$.

In addition, there is a confusing terminology in the classification system of these injuries. In a recent review of literature, hamstring tears have been classified in grade I, II and III (22). Grade I injuries were defined as minor tears, without rupture of the musculotendinous junction (MTJ), with little edema, mild pain, and no or minimal functional impairment. Grade II injuries were considered major injuries, with partial rupture of the MTJ, or an isolated complete rupture of one component of the muscular complex. For example, an isolated complete rupture of the semimembranosus or biceps femoris, was considered a grade II injury because the rest of the complex was intact. A grade III injury was a complete rupture of the muscular complex, which often coincides with the avulsion of tendons from their proximal insertion on the ischial tuberosity (23). Indications for surgical treatment of proximal hamstring injuries are not clear, nor supported by level I or II studies. This may depend on several reasons: the complexity of the anatomical region, the lack of a universally accepted classification, different functional demands of the patients, and the expertise of the surgeon. Despite this lack of evidence, more and more surgical repairs have been recently carried out in case of complete rupture of the proximal third with a stump retraction greater than $2 \mathrm{~cm}$, or partial rupture with disruption of the proximal insertion in patients who already underwent reconstruction of the anterior ipsilateral cruciate ligament with gracile and semitendinosus tendons (23). Chronic pain and functional impairment despite specific physiotherapy should be considered as other indications to surgical repair, as well as patient's age and functional demands.

Surgical timing is important since acute lesions operated within 4 weeks have reported better results than chronic ones (4-6 months). Actually, some authors suggest surgery

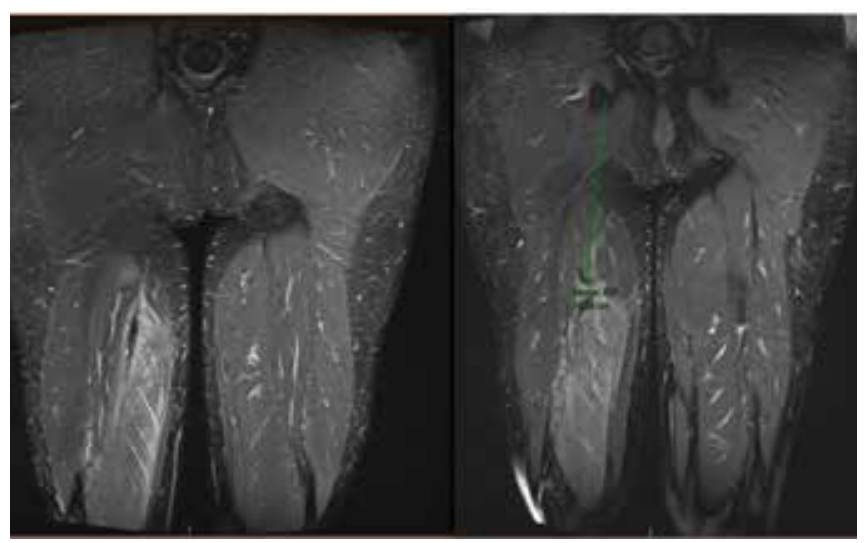

Figure 2. This picture shows a muscle injury type 4 of the semimembranosus muscle of a 47 years old patient. The injury occurred during practice martial arts. Muscle tear on semimembranosus occurred $16 \mathrm{~cm}$ lower than ischiatic tuberosity, and muscle insertion appears continuous. The patient was treated conservatively. A relapse occurred 3 months after injury, during the rehabilitation program. After 1 year, the patient returned to practice martial arts, but he referred occasionally light pain. 
within 2 weeks (23). A systematic review on 18 studies and more than 300 cases of proximal hamstring injury confirmed this data: surgical treatment achieved better results in terms of pain, functional recovery and return to sports than conservative treatment, and patients who underwent surgical repair within 4 weeks from injury showed better outcomes and lower recurrence rates than patients treated after 4 weeks (24) However, this review takes into account only complete proximal hamstrings injuries (avulsions), while there are no data on the partial ones.

The problem gets even more complicated when dealing with MTJ injuries, the so-called partial injuries, for which the literature is extremely poor. Lampainen et al. (25) published a paper in 2006 on 48 athletes who underwent surgical treatment for a partial lesion with tendon involvement of the hamstring, reporting good to excellent results with resumption of the previous sporting activities in $88 \%$ of cases. Recently, an increasing number of authors is surgically treating partial lesions of the myotendinous junction in high level athletes (23). However, there is no scientific evidence yet.

\section{Adductor muscles}

Sports-related groin injuries are common among athletes. Of injuries within this region, $64 \%$ involved the adductor muscle complex. The mechanism of injury typically involves a noncontact, eccentric load with forced abduction and extension of the hip, resulting in disabling groin pain (26). Adductor muscles injuries account for about $20 \%$ of all muscle injuries in athletes. Most adductor ruptures occur at the proximal or distal MTJ, while less frequently proximal or distal adductor tendons avulsion occur. These injuries are predominantly seen in the athletic male population, and the most commonly injured adductor muscle is the adductor longus muscle. Injuries at the MTJ are traditionally treated conservatively with satisfactory outcome, but there are no reports in literature about the surgical repair of adductor muscles injuries.

Management of proximal adductor avulsion injuries is controversial. Nonoperative management for an acute avulsion generally provide good results (27). However, this treatment may result in continued groin pain and decreased function. So, some authors actually suggest that surgical fixation, and surgical reattachment with boney anchors seems to provide better outcomes, shorter return to sports, and significant improvement in outcome scores compared to non-operative treatment $(28,29,30,31)$ However, few case series and case reports are published in literature. Finally, adductor tenotomy has been advocated for chronic groin injuries in some cases (32).

\section{Gastrocnemius muscle}

Cheng et al. (33) published 2 cases treated surgically for a large close injury of the belly of the medial gastrocnemius muscle. The first was a 37 years old patient, treated within 10 days from injury, while the second patients, a 43 years old woman, was treated surgically 7 months post-injury. In both cases MRI showed a complete rupture of medial gastrocnemius belly at the muscle-tendon junction, and a retraction of the muscle fibers. Both patients return to sport at 2- and 10 -months post-surgery (respectively). The patient with the neglected injury referred light pain, which does not limit her activity. For this reason, the authors suggested to perform the surgery during the acute phase. Millers also reported good results in a patient affected by a neglected tear of the medial gastrocnemius muscle, who was not able to walk on tiptoes before surgery (34).

\section{Laceration injury and open wound}

Disinfection and surgical treatment of a muscle laceration caused by direct trauma with sharp objects (e.g. cutting wound) is mandatory. Surgical treatment should be performed immediately (figure 3). Optimal results are reported after the suture of wide muscle laceration (figure 4) $(35,36)$. However, few case reports are available in literature.

\section{Intramuscular calcification}

Currently, there are no evidence-based recommendations about the exeresis of post-traumatic muscle calcifications, since few level IV studies and case reports have been published $(37,38,39)$. Intramuscular calcifications (myositis ossificans) usually arise from large injuries with extensive intramuscular hematoma, but their pathogenesis is not clearly understood yet. However, the onset of calcifications delays the healing process and may result in a significant functional impairment, especially for the large ones. Calcifications typically occur in young male athletes, and commonly affect the quadriceps, the hamstrings, and biceps brachii (40). The incidence is not clear yet, and it ranges from $0.5 \%$ to $9 \%$ after a direct injury, according to authors $(41,42)$.

The diagnosis of myositis ossificans should be considered if pain and swelling persist after 10-15 days post proper conservative management, or if symptoms worsen after 2-3 weeks from the trauma (43). The patients commonly report swelling and stiffness. A reduction of the ROM is usually observed at the clinical examination. MRI is useful since the early stages, while $\mathrm{X}$-rays become positive after about 2-3 weeks and evident after about 2 months. 


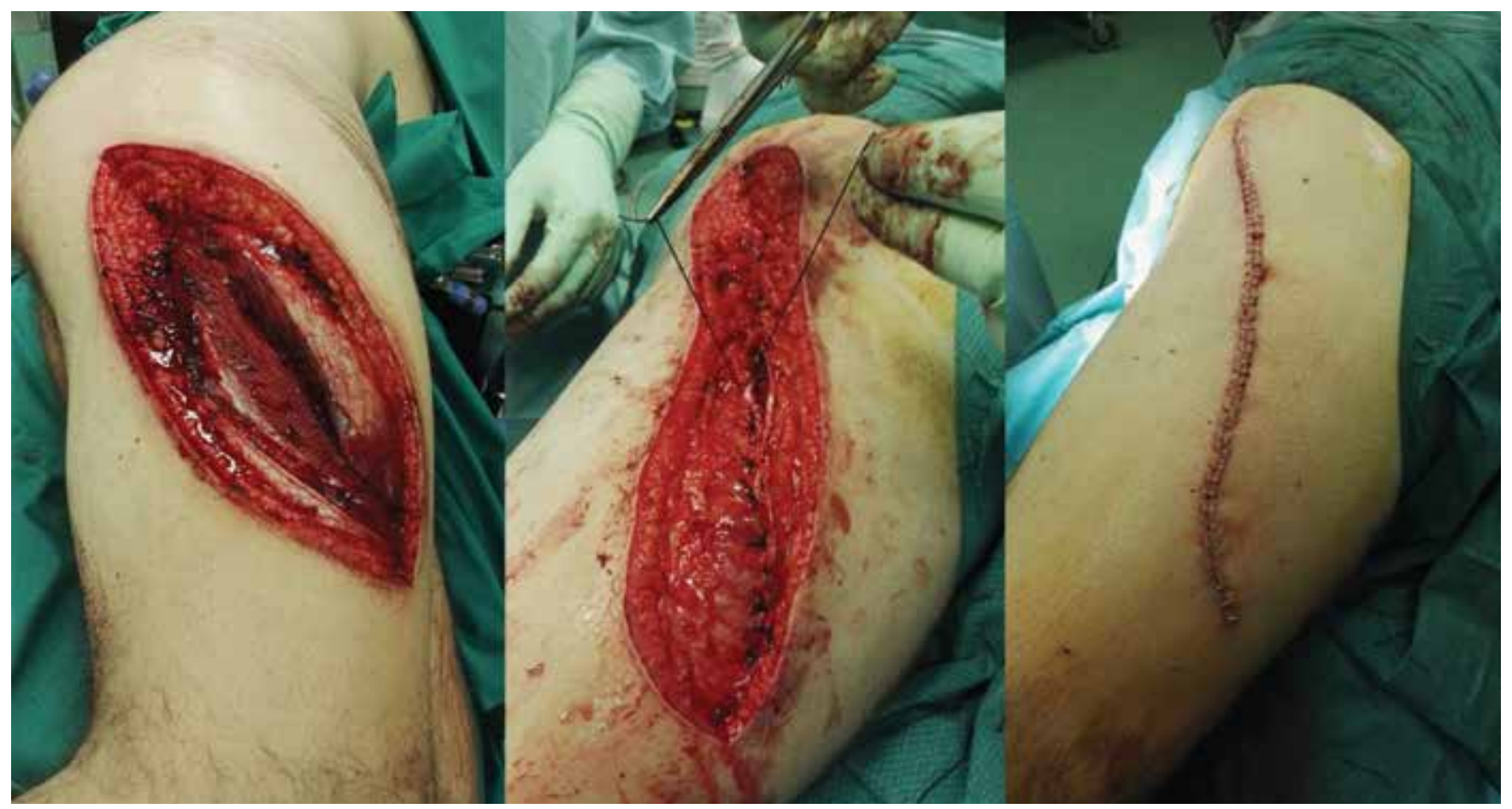

Figure 3. Laceration wound caused by a ski injury. Total vastus lateralis muscle tear in 19 years old guy.

The treatment of the myositis ossificans is conservative first. A few studies showed that the majority of the patients treated with specific rehabilitation protocol return to sport at the same level before the injury, even if the rehabilitation process is longer than an isolated muscle injury $(44,45)$. When calcifications, instead, cause pain and functional impairment, the majority of authors agree on their surgical removal. Surgical exeresis of a calcification should be performed 12 to 24 months after the end of the pathogenetic process. Commonly, an open procedure is performed, although some authors described the arthroscopic exeresis in case of calcifications at the rectus femoris insertion (46). Recently, Orava et al. (47) reported good to excellent results in more than $80 \%$ high-level athletes who underwent the exeresis of calcifications at the proximal third of their hamstrings. In these cases, the surgical exploration and neurolysis of the sciatic nerve is essential because it be trapped by scar tissue and be a source of pain.

\section{What are the most common postoperative complications?}

The most frequent complication, besides the failure of the suture itself, is the post-surgical hematoma. However, there are no information about the incidence, nor whether the use of low molecular weight heparin (LMWH) may promote this complication. There is no indication about the use of postoperative drainage or a compression bandage to reduce the incidence of the complication. Post-surgical hematoma is a despicable complication because it delays the rehabilitation of the patient and may promote the formation of scar tissue and intramuscular calcifications. Surgical evacuation may be indicated for the largest ones (8).

\section{CONCLUSIONS}

Muscle injuries are frequent, and often occur during sporting activities. Type 2 and 3 injuries are treated conservatively with excellent results, while conservative treatment of type 4 injuries does not always produce the desired outcomes, particularly in high level athletes. Surgical suture of type 4 muscle injuries seems to provide good outcomes with a high rate of return to sports activities, reducing the complications and recurrence's rate. Suture of the muscular fibers together with the epimysium improves the suture stability, allowing an earlier and safer mobilization. However, there are no level I nor II studies supporting surgical treatment of muscle injuries. Therefore, we need studies with a higher 


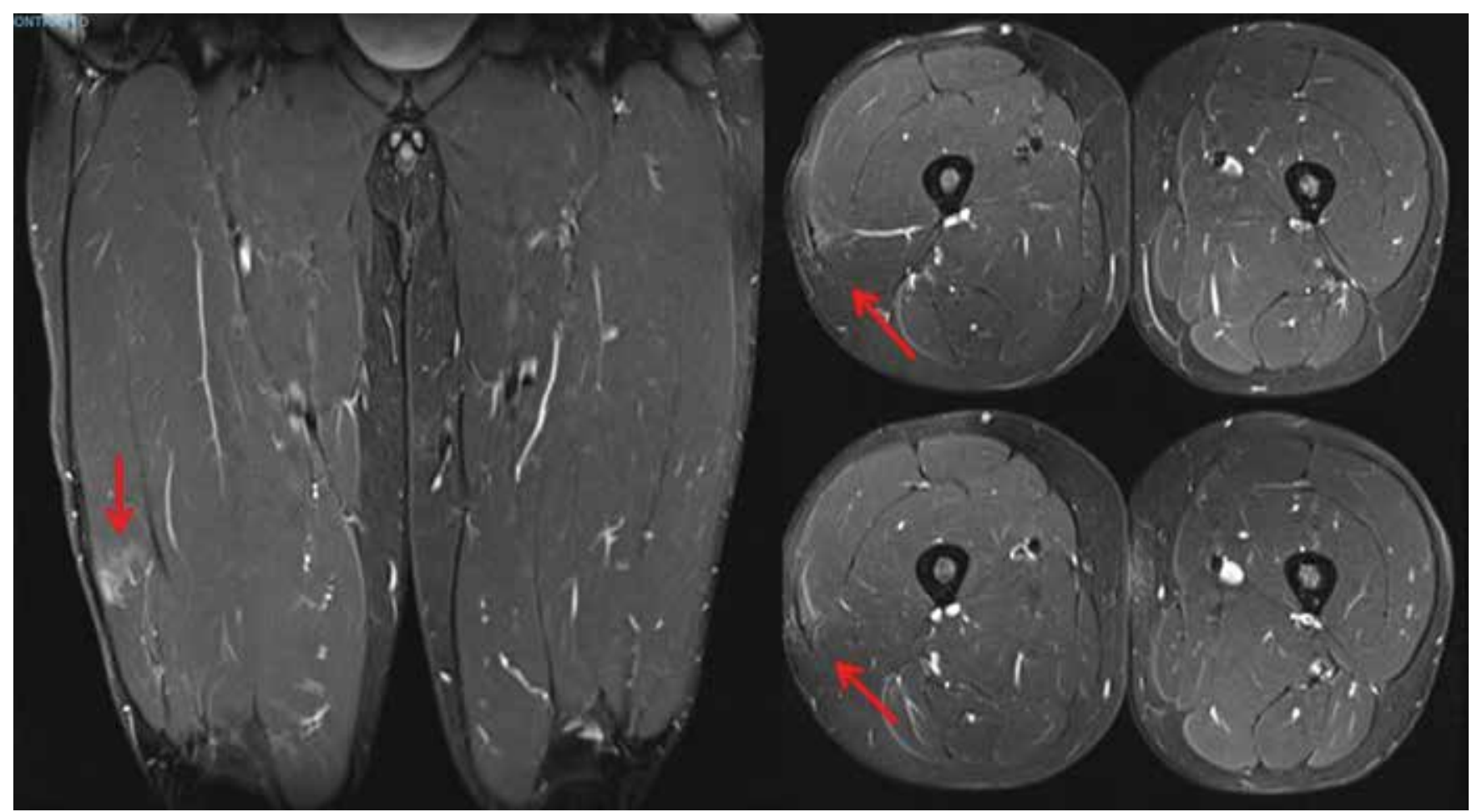

Figure 4. MRI scan 1 year post-injury. The patient returns to play volleyball at the pre-injury level pain free.

scientific evidence to improve our knowledge, in order to guarantee the best treatment to our patients.

\section{KEY POINTS}

- Early mobilization, compared to immobilization, can improve the healing process and stimulate the formation of more functional muscle tissue.

- The suture of muscle fibers together with epimysium improves the mechanical resistance and reduce suture pull-out.

\section{REFERENCES}

1. Maffulli N, Oliva F, Frizziero A et al. ISMuLT Guidelines for muscle injuries. Muscles Ligaments Tendons J. 2014;24;3: 241-9.

2. Maffulli N, Del Buono A, Oliva F, Muscle Injuries: A Brief Guide to Classification and Management. Transl Med UniSa. 2014; 1;12: 14-8.

3. Padulo J, Oliva F, Frizziero A, Maffulli N. Muscles, Ligaments and Tendons Journal - Basic principles and recommendations in clinical and field Science Research: 2018 update. MLTJ 2018; 8(3): $305-307$.

4. Jozsa L, Kannus P, Thoring J, et al. The effect of tenotomy and immobilization on intramuscular connective tissue. J Bone Joint Surg. 1990; 72:293-297.
- The suture of type 4 muscle injuries seems to improve the outcomes and to reduce the recurrence rate.

- There is no evidence about the timing of surgery, nor the age of the patients. Few articles showed that the outcomes of acute muscle injuries are better compared to chronic injuries.

\section{CONFLICT OF INTERESTS}

The authors declare that they have no conflict of interests.

5. Jarvinen MJ, Lehto MUK. The effects of early mobilization and immobilization on the healing process following muscle injuries. Sports Med. 1993; 15:78-89.

6. Kragh JF Jr, Basamania CJ. Surgical repair of acute traumatic closed transection of the biceps brachii. J Bone Joint Surg [Am]. 2002; 84: 992-998.

7. Botte MJ, Gelberman RH, Smith DG, et al. Repair of severe muscle belly lacerations using a tendon graft. J Hand Surg [Am]. 1987;12: 406-12.

8. Lempainen L, Kosola J, Niemi P, et al. Complete midsubstance rectus femoris ruptures: a series of 27 athletes treated operatively. Muscles, Ligaments, Tendons Journal. 2018; 8: $276-282$. 
9. Taylor C, Yarlagadda R, Keenan J. Repair of rectus femoris rupture with LARS ligament. BMJ Case Rep. 2012.20;2012. pii: bcr0620114359.

10. Cheng Y, Yang HL, Sun ZY, et al. Surgical Treatment of Gastrocnemius Muscle Ruptures. Orthop Surg. 2012.4:2537.

11. Orava S, Hetsroni I, Marom N, et al. Surgical Excision of Posttraumatic Ossifications at the Proximal Hamstrings in Young Athletes. Technique and Outcomes. The American Journal of Sports Medicine. 2015; 43:1331-6.

12. Kragh JF Jr, Svoboda SJ, Ward JA, Walters TJ. Passive biomechanical properties of sutured mammalian muscle lacerations. Journal of Investigative Surgery. 2005; 18:19-23.

13. Kragh JF, Svoboda SJ, Wenke JC, et al. Suturing of lacerations of skeletal muscle. J Bone Joint Surg Br. 2005; 87:1303-5.

14. Kragh JF Jr, Svoboda SJ, Wenke JC, et al. Epimysium and Perimysium in Suturing in Skeletal Muscle Lacerations. J Trauma. 2005; 59:209-212.

15. He M, Sebastin SJ, Gan A, et al. Biomechanical comparison of different suturing techniques in rabbit medial gastrocnemius muscle laceration repair. Ann Plast Surg. 2014; 73:333-5.

16. Crow BD, Haltom JD, Carson WL, et al. Evaluation of a novel biomaterial for intrasubstance muscle laceration repair. Orthop Res 25:396-403, 2007.

17. Goyal KS, Speeckaert A, Goitz RJ, et al. A comparison of barbed suture versus traditional techniques for muscle belly repair. Hand. 2018; 1-4.

18. Heckman JD, Levine MI. Traumatic closed transection of the biceps brachii in the military parachutist. J Bone Joint Surg Am. 1978; 60:369-72.

19. Straw R, Colclough K, Geutjens G. Surgical repair of a chronic rupture of the rectus femoris muscle at the proximal musculotendinous junction in a soccer player. Br J Sports Med 2003; 37:182-4.

20. De Smet AA, Best TM. MR imaging of the distribution and location of acute hamstring injuries in athletes. AJR 2000; 174:393-399.

21. Lempainen L, Sarimo J, Mattila K, et al. Distal tears of the hamstring muscles: review of the literature and our results of surgical treatment. Br J Sports Med. 2007; 41:80-83.

22. Lempainen L, Banke IJ, Johansson E, et al. Clinical principles in the management of hamstring injuries. Knee Surg Sports Traumatol Arthrosc. 2015; 23:2449-56.

23. Askling CM, Koulouris G, Saartok T, et al. Total proximal hamstring ruptures: clinical and MRI aspects including guidelines for postoperative rehabilitation. Knee Surg Sports Traumatol Arthrosc. 2013; 21:515-533.

24. Harris JD, Griesser MJ, Best TM et al. Treatment of proximal hamstring ruptures - a systematic review. Int J Sports Med. 2011; 32:490-495.

25. Lempainen L, Sarimo J, Heikkila“ J, et al. Surgical treatment of partial tears of the proximal origin of the hamstring muscles. Br J Sports Med. 2006; 40:688-691.

26. Mosler AB, Weir A, Eirale C et al. Epidemiology of time loss groin injuries in a men's professional football league: a 2 -year prospective study of 17 clubs and 606 players. Br J Sports Med. 2018; 52:292-297

27. Schlegel TF, Bushnell BD, Godfrey J, Boublik M. Success of nonoperative management of adductor longus tendon ruptures in National Football League athletes. Am J Sports Med. 2009; 37:1394-1399.

28. Srino Bharam S, Feghhi DP, Porter DA, Bhagat PV. Proximal adductor avulsion injuries outcomes of surgical reattachment in athletes. The Orthopaedic Journal of Sports Medicine, 2018.6;7.

29. Tansey RJ, Benjamin-Laing H, Jassim S, Liekens K, Shankar A, Haddad FS. Successful return to high-level sports following early surgical repair of combined adductor complex and rectus abdominis avulsion. Bone Joint J. 2015;97-B:1488-92.

30. Vogt S, Ansah P, Imhoff AB. Complete osseous avulsion of the adductor longus muscle: acute repair with three fiberwire suture anchors. Arch Orthop Trauma Surg. 2007; 127:613-615.

31. Rizio L III, Salvo JP, Schürhoff MR, Uribe JW. Adductor longus rupture in professional football players: Acute repair with suture anchors: A report of two cases. Am J Sports Med 2004; 32:243-245.

32. Mei-Dan O, Lopez V, Carmont MR, et al. Adductor tenotomy as a treatment for groin pain in professional soccer players. Orthopedics. 2013;36:e1189-e1197.

33. Cheng Y, Yang HL, Sun ZY, et al. Surgical Treatment of Gastrocnemius Muscle Ruptures. Orthopaedic Surgery 2012; 4:253-257.

34. Miller WA. Rupture of the musculotendinous juncture of the medial head of the gastrocnemius muscle. Am J Sports Med, 1977, 5: 191-193.

35. Oliva F, Giai Via A, Kiritsi O, et al. Surgical repair of muscle laceration: biomechanical properties at 6 years follow-up. Muscles, Ligaments and Tendons Journal 2013; 3: 313-317.

36. Julien TP, Mudgal CS. Anchor suture technique for muscle belly repair. Tech Hand Surg 2011;15: 257-259.

37. Orava S, Hetsroni I, Marom N, et al. Surgical excision of posttraumatic ossifications at the proximal hamstrings in young athletes. Technique and Outcomes. The American Journal of Sports Medicine. 2015; 43:1331-1336.

38. Guan Z, Wilson TJ, Jacobson JA, et al. Delayed sciatic nerve injury resulting from myositis ossificans traumatic. $\mathrm{PM} \& \mathrm{R}$ 2016; 8:484-487.

39. Srikanth IM, Vishal A, Kiran KR. Myositis ossificans of rectus femoris: a rare case report. J Orthop Case Rep. 2015; 5:92-94.

40. Järvinen TA, Järvinen TL, Kääriäinen M, et al. Muscle injuries: biology and treatment. Am J Sports Med. 2005; 33:745-764.

41. Ryan JB, Wheeler JH, Hopkinson WJ, et al. Quadriceps contusions: West Point update. Am J Sports Med. 1991; 19:299-304.

42. Ouellette H, Thomas BJ, Nelson E, et al. MR imaging of rectus femoris origin injuries. Skeletal Radiol 2006; 35: 665-672.

43. Sodl JF, Bassora R, Huffman GR, et al. Traumatic myositis ossificans as a result of college fraternity hazing. Clin Orthop Relat Res. 2008; 466:225-230.

44. Cooper DE. Severe quadriceps muscle contusions in athletes. Am J Sports Med. 2004; 32:820-826.

45. Ryan JB, Wheeler JH, Hopkinson WJ, et al. Quadriceps contusions. West Point update. Am J Sports Med. 1991; 19:299-304.

46. El-Husseiny M, Sukeik M, Haddad FS. Arthroscopic excision of heterotopic calcification in a chronic rectus femoris origin injury: a case report. Ann R Coll Surg Engl. 2012; 94:129-131.

47. Orava S, Sinikumpu J, Sarimo J, et al. Surgical excision of symptomatic mature posttraumatic myositis ossificans: characteristics and outcomes in 32 athletes. KSSTA 2017 25:3961-3968. 